\title{
Extrinsic and Intrinsic for online Classroom
}

\author{
Yuwanuch Gulatee $^{1}$, Babara Combes ${ }^{2}$, Yuwadee Yoosabai ${ }^{3} \&$ Piyaphisak Jaerasukon $^{4}$ \\ ${ }^{1}$ School of Management and Information Technology, Nakhonphanom University, Nakhonphanom, Thailand \\ ${ }^{2}$ School of Information Studies Charles Sturt University, Australia \\ ${ }^{3}$ English Language Teaching Department, Panyapiwat Institute of Management, Bangkok, Thailand \\ ${ }^{4}$ School of Management and Information Technology, Nakhonphanom University, Nakhonphanom, Thailand \\ Correspondence: Yuwanuch Gulatee, School of Management and Information Technology, Nakhonphanom \\ University, Nakhonphanom, Thailand. Tel: 66-42-587-288. E-mail: ygulatee@ npu.ac.th; ygulatee@ gmail.com
}

Received: October 23, $2021 \quad$ Accepted: November 18, $2021 \quad$ Online Published: November 24, 2021

doi:10.5539/hes.v12n1p1 URL: https://doi.org/10.5539/hes.v12n1p1

\begin{abstract}
The objectives of this research are 1) to examine how Thai youth in tertiary education feel about extrinsic and intrinsic rewards when studying online.2) to explore any similarities and differences between the two techniques. 3 ) to determine how students felt about the reward system used in this class. The samples in this research are 37 students. They are all the students who study in an online classroom for the whole semester during the COVID19 global pandemic (2019-2021).The questionnaire and the interview instruments were designed to clarify participants' attitude and used a five point Likert scales and the entire reliability value is 0.80 . The statistics used for data analysis were included descriptive statistics; and proportion and percentage, and inferential statistics such as multiple regression and Chi-square- test. The result disclose as follows : 1) The students showed that all of the four dimensions of this variables test of which one variables is extrinsic, have significant, positive relationships with satisfaction $(\mathrm{r}=.690, \mathrm{p}<0.01)$. 2) The results indicate that extrinsic and intrinsic variables had a negative effect on satisfaction $(\beta=.051, \mathrm{p}>0.01),(\beta=.252, \mathrm{p}>0.01) .3)$ the results indicate that Feelings had a positive effect on satisfaction $(\beta=.638, \mathrm{p}<0.01)$ and could predict satisfaction variables by 56.1 percent (adjusted $\left.R^{2}=0.561\right)$, and extrinsic and intrinsic variables had a negative effect on satisfaction ( $\mathrm{p}>0.01$ ).
\end{abstract}

Keywords: online education, extrinsic, intrinsic, attitude toward online education, Thailand higher education; e-learning

\section{Introduction}

\subsection{Introduce the Problem}

The use of online education have increased during the COVID19 global pandemic (2019-2021) because it allows schools and universities to continue the education of their students. To provide a range of equitable educational opportunities for students, many universities have consider on developing an online distance education programs for higher educations. Technology allows people to communicate and learn easily one-to-one and one-to-many, and individuals. Study online helping individuals to conduct their personal and professional lives wholly online. Students can also complete educational programs wholly online or via blended learning programs. Interesting question how they are used by teachers and students as technologies are integrated into educational settings. However, research is telling us that technology only works if it is embedded into learning programs and students are taught how to use it for learning purposes (Gulatee, 2017; Gultee, Rungsuk \& Combes 2020). Online students require a range of different skills to engage with and interrogate eLearning materials. Lack of motivation and uncertainty are barriers to the successful engagement of students in online learning (Combes \& Anderson, 2006; Combes \& Corroll, 2013). While using reward systems to motivate students has been and continues to be widely used in education, it is rarely recognized or included in adult education and university level study by educators. However, teaching is not just about delivering content to students. Teaching is about guiding students, especially in adult education, to develop complex understandings of knowledge, make connections and acquire higher order thinking skills that are transferrable to all aspects of study and life. The best lessons, books, and materials in the world will not get students excited about learning, nor will they be motivated to work hard at their chosen subjects. A well-designed curriculum will help students to make the cognitive connections on their learning journey, but it is the teacher who plays a pivotal role in the learning that 
takes place in the classroom. The key role of the teacher is even more important in online education, where lack of motivation is a major factor in retention rates and academic success. Research into online courses has clearly shown that students consider the teacher to be one of the most important components of the online study process (Combes \& Anderson, 2006; Combes \& Corroll, 2013; Gulatee, 2010) where feedback and student-teacher communication is essential to keep students engaged in their study. The same is true for face-to-face classrooms, particularly where students also have access to study materials online. One of the most difficult aspects of being a teacher is learning how to sustain student engagement and motivation, particularly when working with adult learners. Research by Tranquillo and Stecker (2016) found that "motivation supports engagement that leads to actions that make a change in the environment". This can be particularly important when students need to complete homework assignments, tedious work-related projects and exams which they find difficult or not interesting. When students are motivated, they are more likely to learn more effectively and enjoy the learning experience. Therefore, a key factor in academic success for students, particularly in adult education, is motivation.

This paper describes a practical classroom program where the author implemented a transparent reward system of small gifts (coffee voucher) and marks. The inclusion of an active and transparent reward system was to motivate student learning and engagement, maintain student attendance in the face-to-face class, and discover which type of reward students preferred

\subsection{Literature Review}

Creating an environment that is conducive to learning is an important role for the teacher. The environment includes tangible aspects such as light, comfortable seating, technology and tools, and the delivery of a well-designed curriculum. However, teaching is a personal relationship between the teacher and the learner. This aspect is intangible and includes how students feel about the person delivering the learning and how the teacher guides and supports the students as they make the learning connections. Effective teachers recognise the importance of using praise and rewards to maintain motivation in the classroom and to establish a strong connection between the teacher and the learner.

There are two ways to motivate students using a reward system. Rewards are either intrinsic or extrinsic or, put another way, as internal or external motivators. Extrinsic motivation occurs when we are motivated to perform a behaviour or engage in an activity to earn a reward or avoid punishment. In this case, you engage in behaviour, not because you enjoy it or because you find it satisfying, but to get something in return or avoid something unpleasant (Deci, Koestner, Ryan \& Cameron, 2001). Rewards give students a sense of accomplishment and encourage them to work with a goal in mind. Everyone likes getting rewards, and offering students the chance to earn them is an excellent way to motivate them. When using a method that works on extrinsic rewards, the teacher should consider the personalities and needs of students to determine appropriate rewards for the class (Morris, 2008). Extrinsic motivation is one way to motivate your students and may include stamps/stars (for younger children), phone cards or coffee vouchers, marks, or movie tickets. An extrinsic reward is different to an intrinsic reward, which originates inside the individual student (Anderman\& Anderman, 2014; Schunk, Pintrich \& Meece, 2008). Cherry (2019) maintains that it is important to understand that the rewards can be either tangible (extrinsic) or psychological (intrinsic) in nature. However, extrinsic rewards can also have a psychological effect on the individual student and motivate them to continue to do well, as their sense of self-worth and confidence (internal/intrinsic) is boosted by the public recognition that accompanies the receipt of the (tangible) reward.

Intrinsic rewards involve the engagement of a person's feelings of satisfaction because they have performed a task well. The individual is motivated to continue to do well to experience these feelings of self-gratification and personal promotion again. The reward is not visible or tangible, but invisible and internalized by the individual as feelings of satisfaction and a positive sense of self, which in turn leads to an increase in self-confidence. For example, a woman who likes to clean the house, because she experiences feelings of satisfaction when it is clean, is experiencing an intrinsic reward. She is then motivated to keep the house clean. If someone compliments her on the cleanliness of the house, her feelings of satisfaction increase and the motivation to keep the house clean are even stronger (Deci, Koestner, Ryan \&Cameron, 2001; List, Livingston \& Neckermam,2018). An intrinsic reward becomes a motivating factor that has long-lasting repercussions on the individual as it affects behaviour and feelings of self, as well as creating feelings of satisfaction. "Intrinsic motivation is a behaviour that is energized by the pleasure derived from engaging in the activity. Students high in intrinsic motivation will engage in tasks because of curiosity, a desire for challenge and a sense of enjoyment associated with the study. This is the most autonomous form of motivation as behaviour is completely initiated and regulated by the individual" (Hill,2013 p.244). Hill also concluded that autonomous motivation provided an ongoing source of positive 
emotional experiences and behavioural commitment from the students (Hill, 2013). Intrinsic motivation, therefore, has a much deeper and possibly more lasting effect on the individual and their motivation to continue learning.

Motivation in the classroom has a major effect on how students approach and feel about their learning and the teacher-learner relationship. It is an important way of engaging students in the lower levels of education, but it is also very effective at adult education including university level. Using a reward system in the tertiary classroom is not common practice as there appears to be a belief that rewards are only for younger students and children. However, adults respond to rewards as much as children and rewards can have an impact on motivation and how much students engage in their learning. This paper describes how university students in an online classroom felt about a transparent reward system, their preferences for extrinsic or intrinsic rewards, and whether the rewards had a motivational effect on their engagement and participation in the classroom.

\section{Method}

The research used both quantitative and qualitative methods to provide a more holistic picture of how young people fell for rewards for online Classroom. Using both types of approaches allows for the triangulation of findings, while using more than one method ensures a more complete description or picture of human behaviour (Jick, 1979; Nachmias \& Nachmias, 1981; Bryman, 2007). Quantitative method in this research used web-based questionnaires. Using the Web is cost effective and time efficient, enables the researcher to gain a snapshot of the current state of affairs, allows for a fast turn-around for data collection (Nancarrow, Pallister, \& Brace, 2001). Web questionnaires also afford participants with anonymity and allows them to answer the questions in a non-threatening and often familiar environment. The research also used qualitative research method in the form of in-depth student interviews that used a structured format in order to achieve consistency and quality assurance.

\subsection{Participants}

The researcher used the whole population of the students in the online classroom because they were a small number (37 students). The researcher and the university ethics officer were identified in the invitation to participants so if potential participants had concerns about the research or research design they could follow up with the researchers involved. Data collected via the online questionnaire was stored within a secured database on a secure server, and transcripts of follow-up interviews were de-identified and kept as digital audio files on a secure desktop PC.

\subsection{Research Objectives}

1. To examine how Thai youth in tertiary education feel about extrinsic and intrinsic rewards when studying online.

2. To explore any similarities and differences between the two techniques.

3. To determine how students felt about the reward system used in this class.

\subsection{Research Methodology}

The research method used quantitative research and qualitative research by categorizing it into two parts as outlined below.

Part 1: Qualitative Research

(1) Documentary research: using the literature review and related research to prepare the basic information for an interview.

(2) Interview: using an informal interview with participants and purposive selection of student volunteers.

(3) Interview form: this was proposed by three experts to examine the validity of each question item. The results of the interview form after being considered by the experts revealed that there were twenty-one question items, the validity of the contents covered each aspect of the questions and covered the research purposes. The measurement results of the Item-Objective Congruence Index (IOC) of the questions were between 0.60 and 1.00, or more than 0.5 . Hence, the questions are robust and can be used for data collection.

\section{Part 2: Quantitative Research}

The researcher selected the participants to answer the questionnaire by using a Purposive Selection method. The researcher selected Thai youth in tertiary education at Nakhon Phanom University. The instrument used for quantitative research was a questionnaire consisting of twelve questions that used a five-point Likert Scale. A five-point Likert scale and descriptive statistics were used for the analysis of the results. The statistics used for 
quantitative data analysis included percentages and mean. Responses from the open-ended survey question provided qualitative data which were transcribed, annotated and coded thematically, with descriptions and assertions (Miles \& Huberman, 1994). Using an iterative analytical approach (Lee, 1994) allowed for an understanding of the text as a whole and the interpretation of its parts, in which descriptions were guided by anticipated explanations. To determine the quality of the questions the following investigation was conducted. The first questionnaire (twelve items) was submitted to three experts who examined the validity of each question. The results of examination after consideration by the experts concluded that all twelve questions were suitably robust to be used for the collection of data.

The questionnaire was designed to clarify participants' attitudes to using online as a mode of access to educational opportunities. Themes for the questions included:

- personal experience of online learning;

- personal reflections about online learning (open-ended question); and

- differences in students' participation and attitudes when extrinsic and intrinsic rewards were used in online learning situations.

\subsection{Research Framework}

This research explores the use of a transparent reward system using extrinsic and intrinsic rewards such as small gifts, marks and praises, rewards and the levels of student satisfaction with their online learning experience. Graduate students in a public university in Thailand participated in this study. The research framework can be summarized as shown below in Figure 1.

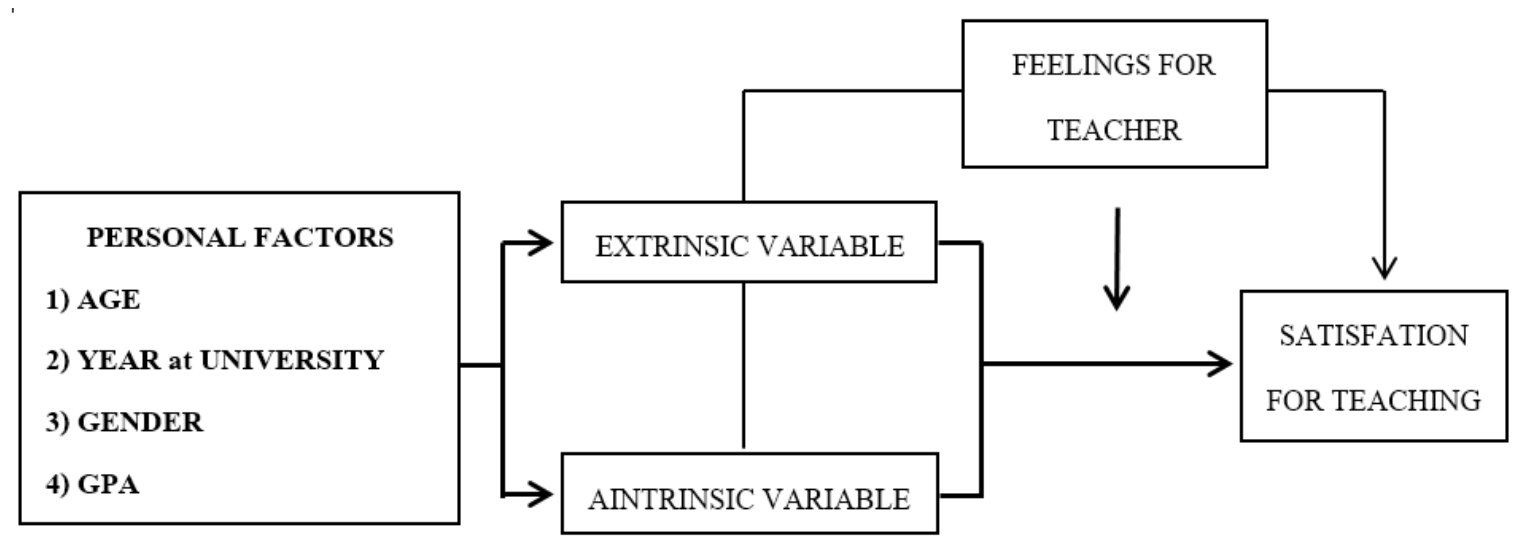

Figure 1. Research Framework

\subsection{Statistical Analysis Data}

Statistical analysis data included descriptive statistics, proportion and percentage, and inferential statistics such as multiple regression and Chi-square- test detailed below:

$$
\begin{aligned}
& \text { Extrinsic Variable } \left.=B 0+B_{1}(\text { Age })+B_{2} \text { (Year at University }\right)+B_{3}(\text { Gender })+B_{4}(\text { GPA. })+E(1) \\
& \text { Intrinsic Variable } \left.=B 0+B_{1}(\text { Age })+B_{2} \text { (Year at University }\right)+B_{3}(\text { Gender })+B_{4}(\text { GPA. })+E(2) \\
& \text { Feelings for Teacher } \left.=B 0+B_{1}(\text { Age })+B_{2} \text { (Year at University }\right)+B_{3}(\text { Gender })+B_{4}(\text { GPA. })+E(3) \\
& \text { Satisfactions for Teaching } \left.=B 0+B_{1}(\text { Age })+B_{2} \text { (Year at University }\right)+B_{3}(\text { Gender })+B_{4}(\text { GPA. })+E
\end{aligned}
$$

Satisfactions for Teaching $=B 0+B_{1}$ (Extrinsic Variable $)+B_{2}$ (Intrinsic Variable $)+B_{3}$ (Feelings for Teacher) $+\mathrm{E}(5)$ 


\section{Findings}

Participants in this research consisted of a range of students who were studying across a public university in the Northeast of Thailand. The total number of participants were 37. The research population is shown in Table 1. As indicated below participants in the research were mostly aged between 19-20 years old (62\%) and studying in the second year (65\%). There are mostly males (65\%, females 35\%) and have a GPA. between 2.00-3.00 (57\%).

Table 1. Research Participants

\begin{tabular}{|c|c|c|}
\hline PERSONAL FACTORS & Proportion & Percentage (\%) \\
\hline \multicolumn{3}{|l|}{ 1.1) AGE } \\
\hline$<18$ & - & - \\
\hline $18-19$ & 4 & 10.8 \\
\hline $19-20$ & 23 & 62.2 \\
\hline $21-22$ & 5 & 13.5 \\
\hline$>23$ & 5 & 13.5 \\
\hline Total & 37 & 100.0 \\
\hline \multicolumn{3}{|l|}{ 1.2) YEAR at UNIVERSITY } \\
\hline 1 year & 5 & 13.5 \\
\hline 2 year & 24 & 64.9 \\
\hline 3 year & 1 & 2.7 \\
\hline 4 year & 7 & 18.9 \\
\hline$>5$ year & 37 & 100.0 \\
\hline \multicolumn{3}{|l|}{ Total } \\
\hline \multicolumn{3}{|l|}{ 1.3) GENDER } \\
\hline Male & 24 & 64.9 \\
\hline Female & 13 & 35.1 \\
\hline Total & 37 & 100.0 \\
\hline \multicolumn{3}{|l|}{ 1.4) GPA } \\
\hline$<1$ & - & - \\
\hline$>1.01$ & - & - \\
\hline$<2.00$ & 4 & 10.8 \\
\hline$<2.01$ & 7 & 18.9 \\
\hline$<3.00$ & 13 & 35.1 \\
\hline$>3.01$ & 8 & 21.6 \\
\hline$<4.00$ & 5 & 13.5 \\
\hline Total & 37 & 100.0 \\
\hline
\end{tabular}

From Table 1, a bivariate correlation analysis of Pearson's correlation was used on all variables. The first purpose is to explore the relationships among variables. Another purpose is to verify the multicollinearity problem. Multicollinearity problems exist when the inter-correlation of variables exceeds 0.80 (Hair, Black, Babin, \&. Anderson, 2010). In this research, the bivariate correlation procedure is subject to a two-tailed test of statistical significance at two levels as $\mathrm{p}<0.05$, and $\mathrm{p}<0.01$.

Results showed that all the four dimensions of this variables test of which one variable is extrinsic, have significant, positive relationships with satisfaction $(\mathrm{r}=.690, \mathrm{p}<0.01)$. The results for the two dimensions classed as intrinsic show significant, negative relationships with satisfaction $(\mathrm{r}=.075, .121 \mathrm{p}>0.01)(\mathrm{Hair}$, Howard \& Nitzl, 2020).

Table 2. Correlation matrix analysis OF Variables Test

\begin{tabular}{lllll}
\hline VARIABLES & SATISFACTION & EXTRINSIC & INTRINSIC & FEELINGS \\
\hline SATISFATION & 1.000 & $.690^{* *}$ & .075 & .121 \\
EXTRINSIC & $.000^{* *}$ & 1.000 & $.375^{*}$ & $.403^{*}$ \\
INTRINSIC & .661 & $.022^{*}$ & 1.000 & $.727^{* *}$ \\
FEELINGS & .475 & $.013^{*}$ & $.000^{* *}$ & 1.000 \\
\hline
\end{tabular}

$\mathrm{N}=37 *$ Correlation is significant at the $.05 * *$ Correlation is significant at the .01

The results of regression analysis are explained in Table 2. Firstly, the results indicate that Feelings had a positive effect on satisfaction $(\beta=.638, \mathrm{p}<0.01)$ and could predict satisfaction variables by 56.1 percent (adjusted R2 $=0.561)$, and extrinsic and intrinsic variables had a negative effect on satisfaction $(\mathrm{p}>0.01)$. 
Table 3. Result of Regression Analysis for the Effects of Independent Variables on Satisfaction

\begin{tabular}{llllll}
\hline \multirow{2}{*}{ Independent variables } & \multicolumn{2}{l}{ Satisfaction } & \multirow{2}{*}{$\mathrm{t}$} & $\mathrm{p}$-value \\
\cline { 2 - 4 } & $\mathrm{B}$ & \multicolumn{2}{l}{ Std. Error } & & \\
\hline Constants & 1.299 & .958 & 1.356 & .184 \\
Extrinsic & .338 & .282 & 1.197 & .240 \\
Intrinsic & .319 & .280 & 1.137 & .264 \\
Feelings & .638 & .109 & 5.875 & $.000^{* *}$ \\
$\mathrm{~F} \quad 16.325$ & $\mathrm{P} .000$ & $\mathrm{Adj} \mathrm{R}^{2}$ & .561 & & \\
\hline
\end{tabular}

* Correlation is significant at the $.05 * *$ Correlation is significant at the .01

The results of regression analysis are explained in Table 3. The results indicate that extrinsic and intrinsic variables had a negative effect on satisfaction $(\beta=.051, \mathrm{p}>0.01),(\beta=.252, \mathrm{p}>0.01)$.

Table 4. Result of Regression Analysis for the Effects of Feeling Variable on Extrinsic and Intrinsic

\begin{tabular}{lllll}
\hline \multirow{2}{*}{ Variables } & \multicolumn{2}{l}{ Feeling } & \multirow{2}{*}{$\mathrm{t}$} & $\mathrm{p}$-value \\
\cline { 2 - 4 } & $\mathrm{B}$ & \multicolumn{2}{l}{ Std. Error } & \\
\hline Constants & 3.239 & 1.047 & 2.302 & .028 \\
Extrinsic & .051 & .445 & .115 & .909 \\
Intrinsic & .252 & .441 & .572 & .571 \\
$\mathrm{~F} \quad .015$ & $\mathrm{P} .000$ & Adj R $^{2}$ & .043 & \\
\hline
\end{tabular}

* Correlation is significant at the $.05 * *$ correlation is significant at the .01

Analysis of the personal factors of age, year of study, gender and GPA found that age had a significant positive relationship with Feelings $(p<0.05)$ However, personal factors do not have any positive relationship with Intrinsic and Extrinsic factors ( $>0.000)$ as shown in Table 5.

Table 5. Critical values for the Chi Square Distribution

\begin{tabular}{|c|c|c|}
\hline \multirow[t]{2}{*}{ PERSONAL FACTORS } & \multicolumn{2}{|c|}{ PERSONAL FACTORS HAD A SIGNIFICANT AFFECT TO EXTRINSIC } \\
\hline & Pearson Chi-Square & Asymp. Sig. \\
\hline AGE & 17.775 & $.275(\mathrm{P}>0.05)$ \\
\hline YEAR at UNIVERSITY & 20.366 & $.158(\mathrm{P}>0.05)$ \\
\hline GENDER & 5.864 & $.320(\mathrm{P}>0.05)$ \\
\hline GPA & 16.925 & $.658(\mathrm{P}>0.05)$ \\
\hline \multirow[t]{2}{*}{ PERSONAL FACTORS } & \multicolumn{2}{|c|}{ PERSONAL FACTORS HAD A SIGNIFICANT AFFECT TO INTRINSIC } \\
\hline & Pearson Chi-Square & Asymp. Sig. \\
\hline AGE & 12.454 & $.644(\mathrm{P}>0.05)$ \\
\hline YEAR at UNIVERSITY & 14.000 & $.526(\mathrm{P}>0.05)$ \\
\hline GENDER & .409 & $.995(\mathrm{P}>0.05)$ \\
\hline GPA & 22.911 & $.293(\mathrm{P}>0.05)$ \\
\hline \multirow[t]{2}{*}{ PERSONAL FACTORS } & \multicolumn{2}{|c|}{ PERSONAL FACTORS HAD A SIGNIFICANT AFFECT TO FEELINGS } \\
\hline & Pearson Chi-Square & Asymp. Sig. \\
\hline$A G E$ & 17.722 & $.038 *(P<0.05)$ \\
\hline YEAR at UNIVERSITY & 14.291 & $.112(\mathrm{P}>0.05)$ \\
\hline GENDER & 2.851 & $.415(\mathrm{P}>0.05)$ \\
\hline GPA & 17.641 & $.127(\mathrm{P}>0.05)$ \\
\hline \multirow[t]{2}{*}{ PERSONAL FACTORS } & \multicolumn{2}{|c|}{ PERSONAL FACTORS HAD A SIGNIFICANT } \\
\hline & Pearson Chi-Square & Asymp. Sig. \\
\hline AGE & 12.848 & $.170(\mathrm{P}<0.05)$ \\
\hline YEAR at UNIVERSITY & 9.219 & $.417(\mathrm{P}<0.05)$ \\
\hline GENDER & 4.746 & $.191(\mathrm{P}<0.05)$ \\
\hline GPA & 15.735 & $.204(\mathrm{P}<0.05)$ \\
\hline
\end{tabular}

* Correlation is significant at the $.05 * *$ correlation is significant at the .01 


\section{Conclusion}

Teaching fully online is not easy to manage for teachers and students (Gulatee, 2010). The improvement of students' online performance using motivation techniques in the classroom is often sporadic and an afterthought in most classrooms especially in education after primary school. With everything else teachers have to do, motivating students using consistent techniques that are open and transparent is not something educators do very often or well. Most lecturers often feel it is easier to motivate students and monitor academic progress in the face-to-face classroom. Many instructors believe that replicating the teaching and learning environment in technical units that in require a lot of hands-on activity, is extremely difficult (Gulatee, 2010). However, this study reveals that motivation techniques for higher education students are important especially in an online environment where the dynamic learning experience between the teacher and the learner is less personal than the face-to-face classroom. Students who are motivated to learn are more likely to graduate from university with positive experiences that will help them to perform better in the workplace and be open to ongoing study to maintain their skills and knowledge base in a world where information and change are key features. Moreover, further research in this area is necessary to examine just what types of extrinsic and intrinsic motivation works best to influence student performance, change behaviours and attitudes towards learning and assist higher education teachers to enhance the teacher-learner dynamic.

\section{Discussion}

The use of motivation is necessary by instructors to motivate the students. Using motivation techniques in the classroom is very important because being motivated is a factor influence to student achievement. It is a science and an art that every teacher should have. The instructor needs to combine the motivation strategies with intrinsic motivation and extrinsic motivation. It is also important how the instructor can develop and implement a curriculum that will motivate students to learn. The instructors themselves must be an active person and always creating incentives to develop their own teaching and learning management on a regular basis.

\section{Suggestions}

Further research for higher education study, in this area is necessary to expand in "Term of these things" (small gift) as a reward. This will create bad habits in the higher education later or not.

\section{References}

Anderman, E. M., \& Anderman, L. H. (2014). Classroom motivation (2nd ed). Pearson Education.

Bryman, A. (2007). Barriers to integrating quantitative and qualitative research. Journal of Mixed Methods Research, 1(1), 8-22. https://doi.org/10.1177/2345678906290531

Combes, B., \& Carroll, M. (2013). Are we there yet? ELearning in library and information science courses in Australia. Education for Information, 29(3-4), 205-218. https://doi.org/10.3233/EFI-130930

Combes, B., \& Anderson, K. (2006). Supporting first year e-learners in courses for the information professions. Journal of Education for Library and Information Science (JELIS), 47, 259-276. https://doi.org/10.2307/40323820

Cherry, K. (2019). Extrinsic Motivation. Retrieved from https://www.verywellmind.com/what-is-extrinsic-motivation-2795164

Deci, E. L., Koestner, R., Ryan, R. M., \& Cameron, J. (2001). Extrinsic rewards and intrinsic motivation in education: reconsidered once again: comment/reply. Review of Educational Research, 71(1), 1-51. https://doi.org/10.3102/00346543071001001

Gulatee, Y. (2010). An investigation into online teaching and the delivery of Computer Science topics: practice. Content and environmental factors $\mathrm{PhD}$ dissertation, Edith Cowan University.

Gulatee, Y. (2017). The education is open: Online Education in Thailand. Sarakam: Chaimonkon Printing.

Gulatee, Y., Rungsuk, A., \& Combes, B. (2020). How do we feel about online teaching and learning. 5th International Conference on Information Technology (InCIT-2020), IEEEXplore. p. 92-97. https://doi.org/10.1109/InCIT50588.2020.9310979

Jick, T. (1979). Mixing qualitative and quantitative methods: Triangulation in action. Administrative Science Quarterly, 24(12), 602-611. https://doi.org/10.2307/2392366

Hair, J. F., Black, W. C., Babin, B. J., \& Anderson, R. E. (2010). Multivariate Data Analysis (7th ed.). Upper Saddle River, NJ: Prentice Hall. 
Hair, J. F., Howard, M. C., \& Nitzl, C. (2020). Assessing measurement model quality in PLS-SEM using confirmatory composite analysis. Journal of Business Research, 109, 101-110. https://doi.org/10.1016/j.jbusres.2019.11.069

Hill, A. P. (2013). Motivation and university experience in first-year university students: a self-determination theory perspective. Journal of Hospitality, Leisure, Sport \& Tourism Education, 13, 244-254. https://doi.org/10.1016/j.jhlste.2012.07.001

Lee, A. S. (1994). Electronic mail as a medium for rich communication: an empirical investigation using hermeneutic interpretation. MIS Quarterly, 18, 143-157. https://doi.org/10.2307/249762

List, J. A., Livingston, J. A., \& Neckermann, S. (2018). Do financial incentives crowd out intrinsic motivation to perform on standardized tests? Economics of Education Review, 66, 125-136. https://doi.org/10.1016/j.econedurev.2018.08.002

Miles, M., \& Huberman, A. (1994). Qualitative data analysis: An expanded sourcebook (2nd ed). Sage Publications: Thousand Oaks, CA.

Morris, L. V. (2008). Education at a crossroads: intrinsic motivation or extrinsic rewards. Innovative Higher Education, 33(1), 1-3. https://doi.org/10.1007/s10755-008-9070-3

Nachmias, D., \& Nachmias, C. (1981). Research methods in the social sciences (2nd ed). New York: St. Martin's Press.

Nancarrow, C., Pallister, J., \& Brace, I. (2001). A new research medium, new research populations and seven deadly sins for Internet researchers. Qualitative Market Research: An International Journal, 4(3), 136-149. https://doi.org/10.1108/13522750110393044

Reeve, J. (2009). Why teachers adopt a controlling motivating style toward students and how they can become more autonomy supportive. Educational Psychologist, 44(3), 159-175. https://doi.org/10.1080/00461520903028990

Schunk, D. H., Pintrich, P. R., \& Meece, J. L. (2008). Motivation in education: theory, research, and applications (3rd ed.). Pearson/Merrill Prentice Hall.

Tranquillo, J., \& Stecker, M. (2016). Using intrinsic and extrinsic motivation in continuing professional education. Surgical Neurology International, 7(8), 197-197. https://doi.org/10.4103/2152-7806.179231

\section{Copyrights}

Copyright for this article is retained by the author(s), with first publication rights granted to the journal.

This is an open-access article distributed under the terms and conditions of the Creative Commons Attribution license (http://creativecommons.org/licenses/by/4.0/). 